\title{
PAPR Reduction and Data Security Improvement for OFDM Technique using Chaos System
}

\author{
Muntadher Kadhim Abdullah, and Ali Jawad Ibada
}

\begin{abstract}
Higher value of Peak to Average Power Ratio (PAPR) in wireless Orthogonal Frequency Division Multiplexing (OFDM) systems makes low power efficiency, several degradation of performance in the transmitting power amplifier, and increases complexity of converters. So, it is important to decrease PAPR to avoid these problems. This paper presents a proposed algorithm to decrease PAPR by generating several Aperiodic PseudoRandom Binary Sequences $\left(\mathrm{APRBS}_{\mathrm{s}}\right)$ using chaos system. The proposed algorithm scrambles information sequence by APRBS, and one sequence would be chosen for transmission which it has smallest PAPR value. To inform the receiver which sequence had been sent, a Side Information (SI) is enclosed with the transmitted sequence. Because SI is very important, convolutional code with Viterbi-Soft Decision Decoding (V-SDD) would be used in this paper to protect SI against channel distortion. Simulation results state that the proposed algorithm gives excellent PAPR reduction performance and approximately same Bit Error Rate (BER) performance over AWGN and flat fading channels comparing with the conventional OFDM system. This means that BER performance does not affected by SI. Finally, in addition to improving PAPR reduction performance, the proposed algorithm provides a good data security due to chaos system as well as reduces the hardware and computational complexities in the conventional PAPR reduction scrambling techniques.
\end{abstract}

Index Terms- OFDM, PAPR, BER, APRBS, Chaos, V-SDD, CCDF, and SI.

\section{INTRODUCTION}

$\mathrm{O}$ FDM is an important type of multi-carrier technique which frequently used in modern wireless standards. The fourth generation (4G) in mobile communication systems uses OFDM technique. OFDM is robust against severe multi-path

Manuscript received April 26, 2019; revised September 2, 2019. Date of publication October 9, 2019. Date of current version October 9, 2019. The associate editor prof. Joško Radić has been coordinating the review of this manuscript and approved it for publication.

Authors are with the Computer Technical Engineering Department, College of Technical Engineering, The Islamic University, Najaf, Iraq (emails: montadher.k@iunajaf.edu.iq, ali.alshukri@iunajaf.edu.iq).

Digital Object Identifier (DOI): 10.24138/jcomss.v15i4.764 fading channels, it provides high spectral efficiency, also it supports high transmission data rate, and it has the ability to face frequency-selective fading with using simple equalization $[1,2]$. All these advantages make it more attractive multicarrier technique wireless communication system. OFDM system uses multiple orthogonal subcarriers $(\mathrm{N})$ which are separated closely, $\left\{f_{n}, n=0,1,2, \ldots, N-1\right\}$. Transmitted symbols would be distributed through these orthogonal subcarriers. In fact, the orthogonality between subcarriers minimizes the interference. To get orthogonality, subcarriers must be separated by multiple of $1 / T$, i.e $\Delta f=\frac{1}{T}$, ( $T$ means duration of OFDM signal). The time domain of the transmitted OFDM signal can be given by the expression below [3]:

$\mathrm{x}(\mathrm{t})=\frac{1}{\sqrt{\mathrm{N}}} \sum_{\mathrm{n}=0}^{\mathrm{N}-1} \mathrm{X}_{\mathrm{n}} \mathrm{e}^{-\mathrm{J} 2 \pi \mathrm{f}_{\mathrm{n}} \mathrm{t}} \quad 0 \leq \mathrm{t} \leq \mathrm{T}$

where $\mathrm{f}_{\mathrm{n}}=\mathrm{n} \Delta \mathrm{f}$.

Equation (1) can be sampled at $\mathrm{kT}_{\mathrm{s}}$ with $\mathrm{T}_{\mathrm{s}}=\frac{\mathrm{T}}{\mathrm{N}}$ to yield the following equation:

$\mathrm{x}(\mathrm{k})=\frac{1}{\sqrt{\mathrm{N}}} \sum_{\mathrm{n}=0}^{\mathrm{N}-1} \mathrm{X}(\mathrm{n}) \mathrm{e}^{-\frac{\mathrm{J} 2 \pi \mathrm{nk}}{\mathrm{N}}} \quad$ for $0 \leq \mathrm{k} \leq \mathrm{N}-1$

Equation (2) is the N-point Inverse Discrete Fourier Transform (IDFT) with modulating data by Binary Phase Shift Keying (BPSK). Efficiently, it must be computed by Inverse Fast Fourier Transform (IFFT). In the receiver, Fast Fourier Transform (FFT) is used to demodulate OFDM symbol [4]. High peak power obtains in the transmitter when $\mathrm{N}$ subcarriers are added together with identical phase [5]. This makes the system to have high PAPR value. High Power Amplifier (HPA) of the transmitter with high PAPR value needs large dynamic range to avoid signal distortion and keep low BER [2]. But, this large dynamic range makes the efficiency of HPA is low and too expensive. Also, Digital to Analog Convertors (DAC) require large dynamic range with high PAPR value. This increases the complexity of converters [6]. Because of all these drawbacks, it is very important to decrease PAPR. Previously, several proposed techniques had been implemented to reduce PAPR value. Based on the mathematical correlation analysis among alternative signals, the authors in [7] presented a new technique to test the effects of different phase sequences in Selective Mapping (SLM) technique. 
Furthermore, according to the proposed criteria, the chaotic phase sequence introduced to improve the PAPR reduction performance in SLM. While in [8], a novel phase sequence set generation based on M-ary chaotic sequence had been suggested to achieve better capability of PAPR reduction performance without affecting on BER performance. Then Concentric Circle Constellation (CCC) mapping proposed to eliminate SI in the receiver. In [9], Iterative Clipping and SLM are combined to get better PAPR reduction performance compared to individual methods. In [10], the adjacent partitioned data are firstly transformed by a Discrete Cosine Transform (DCT) into new modified data. After that, the proposed technique used the classical Partial Transmit Sequence (PTS) method to further decrease PAPR. Later, method in [11] presented a study about a group of techniques based on Walsh-Hadamard Transform (WHT) to reduce PAPR. It concluded that SLM-Double WHT (DWHT)-OFDM technique achieved better PAPR reduction performance.

In this work, a simple scrambling algorithm proposed to improve the performance of OFDM system. This algorithm uses chaos system to generate several PseudoRandom sequences that would be scrambled with the data sequence to produce several random sequences. One of them is selected for transmission with lowest PAPR value. In this way, the proposed algorithm will give excellent PAPR reduction performance as well as good data security.

Comparing with the methods in [7] and [10] which used SLM and PTS, The proposed algorithm is characterized by reducing the hardware and computational complexities in the OFDM scrambling techniques (such as PTS and SLM). Also, the proposed method gives better PAPR reduction performance even when using fewer number of phase sequences. The method in [8], PAPR reduction performance had been discussed only with $\mathrm{N}=64$ while this work discusses until $\mathrm{N}=1024$. Even with large value of $\mathrm{N}$, the proposed method gives good PAPR reduction performance. The authors in [9] used clipping method which distorts the shape of OFDM signal. This leads to degrade BER performance of the OFDM system. While, the proposed method does not distort the shape of the signal. Also, the proposed method gives better PAPR reduction performance. Finally, comparing with SLM-DWHT method in [11], the proposed algorithm requires less SI bits.

The rest of this paper is outlined as follows: Section II briefly describes the PAPR signal and its distribution. Section III shows the proposed algorithm and generation of the PseudoRandom sequences using chaos system. Section IV presents the simulation results and security analysis. The conclusion is given in section V. Finally, Section VI shows the acknowledgement.

\section{PAPR OF OFDM SIGNAL}

\section{A. Introduction to PAPR}

PAPR is ratio between instant peak power within a given time period and its average power during that period. Mathematical expression of PAPR is:

$\operatorname{PAPR}[\mathrm{x}(\mathrm{t})]=\frac{\max _{0 \leq \mathrm{t} \leq \mathrm{T}}\left[|\mathrm{x}(\mathrm{t})|^{2}\right]}{\mathrm{P}_{\mathrm{av}}}$

where $\mathrm{P}_{\mathrm{av}}$ means average power of $\mathrm{x}(\mathrm{t})$.
Equation (3) can be given in terms of magnitude by Crest Factor $(\mathrm{CF})$ as $[4]$

$\mathrm{CF}=\sqrt{\mathrm{PAPR}}$

\section{B. Distribution of PAPR in OFDM System}

Suppose that $E\left[|x(t)|^{2}\right]=1$, PAPR value in (3) will be $\mathrm{N}$ only when all subcarriers are added together with same phase. Meanwhile, probability of appearing maximum PAPR value is very small. Therefore, all researchers focus on probability of finding the signal power that would make the operation of HPA in nonlinear region. Hence, it is necessary to study the distribution of OFDM signal. By using central limit theorem and for large values of $\mathrm{N}(\mathrm{N}>64)$, the imaginary and real values of the time-domain OFDM complex signal become Gaussian distribution. Then the amplitude has Rayleigh distribution [12].

Assume magnitudes of $\left\{\left|\mathrm{x}\left(\mathrm{nT}_{\mathrm{S}} / \mathrm{N}\right)\right|\right\}_{\mathrm{n}=0}^{\mathrm{N}-1}$ are $\left\{\mathrm{Z}_{\mathrm{n}}\right\}$. Suppose that $\mathrm{E}\left[|\mathrm{x}(\mathrm{t})|^{2}\right]=1$, then $\left\{\mathrm{Z}_{\mathrm{n}}\right\}$ are independent and identically distributed (i.i.d.) Rayleigh random variables normalized with its own average power. Then, the probability density function is:

$f_{Z_{n}}(z)=\frac{z}{\sigma^{2}} e^{-\frac{z^{2}}{2 \sigma^{2}}}=2 z e^{-z^{2}}, n=0,1,2, \ldots, N-1$

where $\mathrm{E}\left\{\mathrm{Z}_{\mathrm{n}}^{2}\right\}=2 \sigma^{2}=1$

Here, the peak value of $Z_{n}$ equals to the $C F$ (i.e., $Z_{\max }=C F$, where $\left.Z_{\max }=\max _{\mathrm{n}=0,1,2, \ldots, \mathrm{N}-1} Z_{\mathrm{n}}\right)$. Now, Cumulative Distribution Function (CDF) of $Z_{\max }$ can be given by: [4]

$\mathrm{F}_{\mathrm{Z}_{\max }}(z)=\mathrm{P}\left(\mathrm{Z}_{\max }<\mathrm{z}\right)$

$$
=\mathrm{P}\left(\mathrm{Z}_{0}<\mathrm{z}\right) \cdot \mathrm{P}\left(\mathrm{Z}_{1}<\mathrm{z}\right) \ldots \ldots \mathrm{P}\left(\mathrm{Z}_{\mathrm{N}-1}<\mathrm{z}\right)
$$

where $P\left(Z_{n}<z\right)=\int_{0}^{z} f_{Z_{n}}(x) d x, n=0,1, \ldots, N-1$.

$\mathrm{F}_{\mathrm{Z}_{\text {max }}}(\mathrm{z})=\left(1-\mathrm{e}^{-\mathrm{z}^{2}}\right)^{\mathrm{N}}$

To calculate the probability that makes $\mathrm{CF}$ exceed $\mathrm{z}$, the Complementary CDF (CCDF) is:

$$
\begin{aligned}
\tilde{\mathrm{F}}_{\mathrm{Z}_{\max }}(\mathrm{z}) & =\mathrm{P}\left(\mathrm{Z}_{\max }>\mathrm{z}\right) \\
& =1-\mathrm{P}\left(\mathrm{Z}_{\max } \leq \mathrm{z}\right) \\
& =1-\mathrm{F}_{\mathrm{Z}_{\max }}(\mathrm{z}) \\
& =1-\left(1-\mathrm{e}^{-\mathrm{z}^{2}}\right)^{\mathrm{N}}
\end{aligned}
$$

Equation (7) can be expressed in terms of PAPR as shown in (8): [4]

$$
\mathrm{P}[\mathrm{PAPR}>\delta]=1-\left[1-\mathrm{e}^{-\delta}\right]^{\mathrm{N}}
$$

Equation (8) gives the probability of exceeding PAPR value to a certain threshold level $\delta$.

\section{PROPOSED ALGORITHM}

$\mathrm{CF}$ is high when the input sequence is periodic [13]. The basic idea to reduce PAPR in this paper is making the input sequence aperiodic by being scrambled (multiplied or EX-OR) it with aperiodic pseudorandom binary sequence. Chaos sequences are the best selection (explained later in section $\mathrm{A}$ below) to generate Aperiodic PseudoRandom Binary Sequences $\left(A P R B S_{s}\right)$ which explained in the next subsection In addition to reducing PAPR, $\mathrm{APRBS}_{\mathrm{s}}$ also can be used to secure information. The proposed algorithm in this study can 
be considered as scrambling PAPR reduction technique. These techniques do not deform OFDM signal shape. Thus, there is not spectral re-growth occur. But these techniques have hardware and computational complexities, for example in SLM which uses U IFFT blocks in transmitter and U FFT blocks in receiver, where $U$ means number of phase sequences. In the proposed algorithm, these complexities can be reduced by using one IFFT block in transmitter and one FFT block in receiver. Fig. 1 states the flow chart diagram of the proposed system. The algorithm commences by generating input data block bits and M-APRBS (where $\mathrm{M}$ is number of sequences). Let the input data block is $X_{n}\left\{n=0,1, \ldots, N_{s}-1\right.$ where $\left.N_{s}<N\right\}$ and the $A P R B S_{s}$ are $R_{n}^{m}\left\{n=0,1, \ldots, N_{s}-1\right.$ and $\mathrm{m}=0,1,2, \ldots, \mathrm{M}-1\}$. Each data block $\mathrm{X}_{\mathrm{n}}$ is exclusive-or (XOR) with all $\mathrm{R}_{\mathrm{n}}^{\mathrm{m}}$ which result in $\mathrm{M}$ different aperiodic random binary sequences $B_{n}^{m}$, so that

$\mathrm{B}_{\mathrm{n}}^{\mathrm{m}}=\sum_{\mathrm{m}=0}^{\mathrm{M}-1} \mathrm{X}_{\mathrm{n}} \oplus \mathrm{R}_{\mathrm{n}}^{\mathrm{m}}$

where $\bigoplus$ is XOR operation.

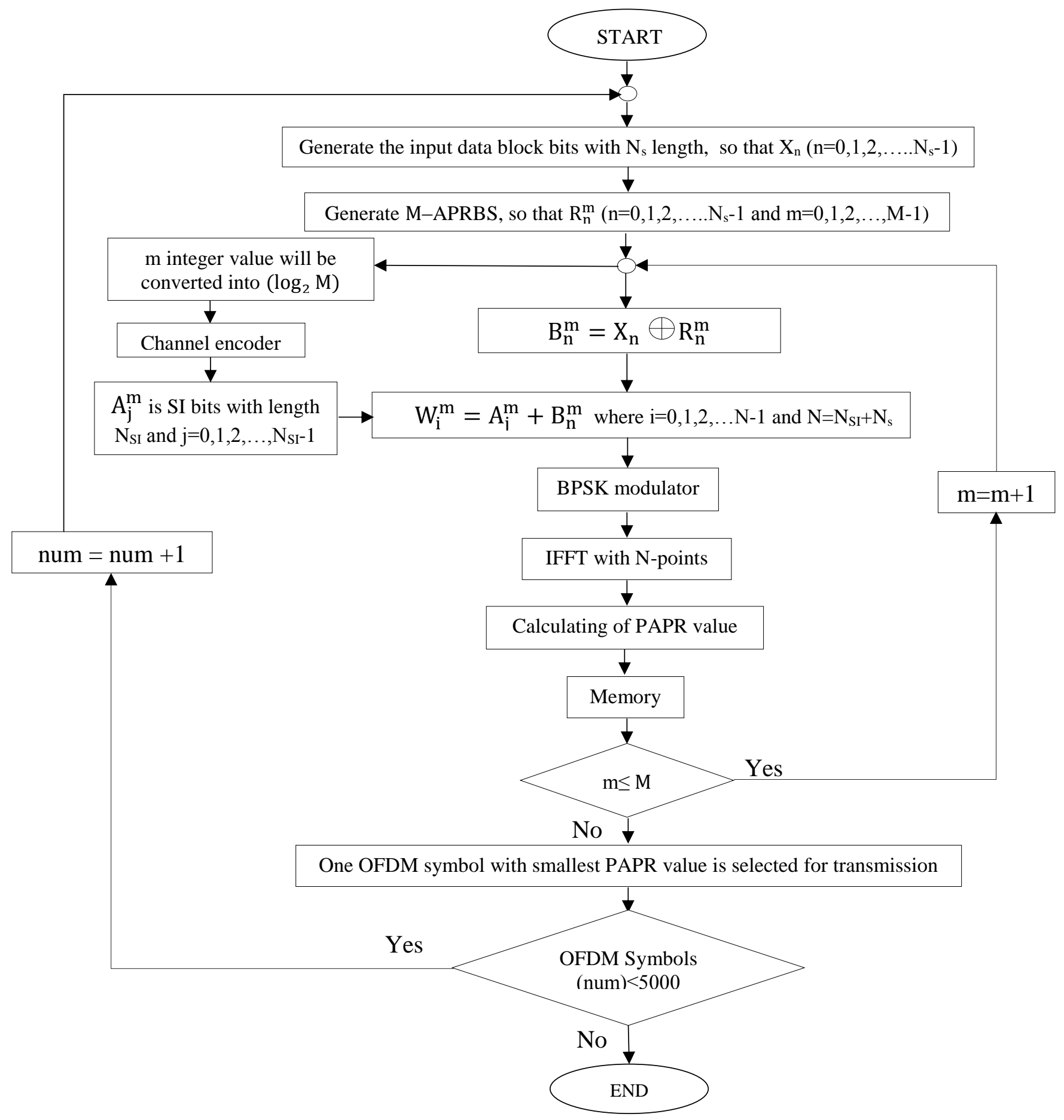

Fig.1. Flow chart of the proposed PAPR reduction technique 
From these $\mathrm{B}_{\mathrm{n}}^{\mathrm{m}}$ sequences, one of them with lowest PAPR value will be chosen for transmission. $m$ is index of an aperiodic sequence, so that $B_{n}^{0}$ is the first sequence, $B_{n}^{1}$ is the second sequence, and etc. Thus, each $\mathrm{m}$ integer value will be converted into $\left[\log _{2}(\mathrm{M})\right]$ binary bits. These bits will be sent to the receiver as a SI. SI must be enclosed with transmitted data to inform the receiver about the sequence which had been used in the transmitter. However, the system performance can be affected if errors occur in SI bits. So that, the whole data block will be lost when receiver detects any error in SI bits. To prevent this problem, a channel coding is used. Section B below explains briefly the type of channel encoder that would be used in this algorithm. The transmitted OFDM signal can be divided into two parts. The first part is information bits $B_{n}^{m}$ and the second part is the encoded SI bits $\left(A_{j}^{m}\right)$, so that

$W_{i}^{m}=A_{j}^{m}+B_{n}^{m}$

where $\mathrm{i}=0,1,2, \ldots, \mathrm{N}-1$ and $\mathrm{j}=0,1,2, \ldots \mathrm{N}_{\mathrm{SI}}-1$.

BPSK constellation can be used to modulate $\mathrm{W}_{\mathrm{i}}^{\mathrm{m}}$ data blocks and using IFFT to get time domain OFDM signal as:

$\mathrm{d}^{\mathrm{m}}(\mathrm{t})=\sum_{\mathrm{i}=0}^{\mathrm{N}-1} \mathrm{~W}_{\mathrm{i}}^{\mathrm{m}} \mathrm{e}^{-\mathrm{J} 2 \pi \mathrm{f}_{\mathrm{i}} \mathrm{t}} \quad 0 \leq \mathrm{t} \leq \mathrm{T}$

In fact, these M-OFDM sequences have the same information. But, these sequences are independent statistically between each other. After that, the PAPR values of $d^{m}(t)$ can be calculated and the signal with smallest PAPR value will be transmitted. Equation (8) when using the proposed method becomes:

$\mathrm{P}(\mathrm{PAPR}>\delta)=\left[1-\left(1-\mathrm{e}^{-\delta}\right)^{\mathrm{N}}\right]^{\mathrm{M}}$

Equation (11) shows that CCDF of the proposed method is much less than CCDF in (8).

\section{A. Aperiodic PseudoRandom Binary Sequences (APRBSs)}

The purpose of generating APRBS is to decrease PAPR value of OFDM signal as well as secure the data. There are several methods to generate APRBS, like the sequences that generated by Linear Feedback Shift Registers $\left(\mathrm{LFSR}_{\mathrm{s}}\right)$, for example Pseudo Noise (PN) sequences, Gold sequences, and Kasami sequences. Another method to generate $A P R B S_{s}$ is the generating of chaotic binary sequence using chaotic maps. Chaos is a non-periodic, random like long-term non-predictive behavior in a deterministic system that exhibits sensitive dependence on initial conditions [14].

Chaotic behavior is a result of the exponential sensitivity of the system to the initial state that cannot be exactly determined in practice [15]. All these properties of chaos sequence make it the best choice in this paper to generate APRBS.

1) Chaotic Map

It is complex, dynamic and non-linear behavior model. It is defined as [16]

$\mathrm{y}_{\mathrm{n}+1}=\mathrm{f}\left(\mathrm{y}_{\mathrm{n}}\right), \mathrm{n}=1,2,3, \ldots$

There are several chaotic maps such as logistic map [17], quadratic map [18], etc. Here, tent map is used to generate APRBS $_{\mathrm{S}}$. It is a discrete time system with one-dimension which apply in many applications [19]. It has the following equation: [20]:

$y_{n+1}=\left\{\begin{array}{cl}\frac{y_{n}}{p}, & 0 \leq y_{n} \leq p \\ \frac{1-y_{n}}{1-p}, & p<y_{n} \leq 1\end{array} \quad n=0,1,2 \ldots\right.$

where $p$ and $y_{n}$ values $\in\{0: 1\}$.

Fig. 2 shows tent map function for two values of $p$ parameter. For a constant $p$, with different $y_{0}$ in (13), a group of trajectories can be obtained. Each trajectory is a sample of random process assigned to (13).

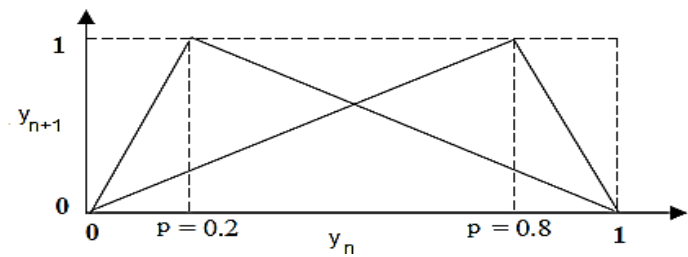

Fig. 2. Tent map when $\mathrm{p}=0.2$ and $\mathrm{p}=0.8$.

Fig. 3 shows this map at $\mathrm{p}=0.2$ and $\mathrm{y}_{\mathrm{n}}=0.1$. While, Fig. 4 states the comparison between two tent map sequences for $\mathrm{p}=0.1$ with $y_{n}=0.1$ and $y_{n}=0.100001$. It's clearly shown that a small change in initial values after few iterations results in different waveforms.

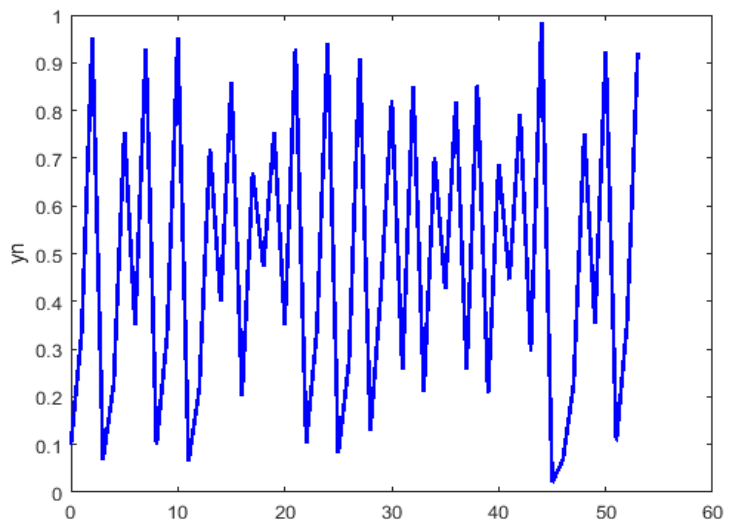

Fig.3. Time series plot for the tent map

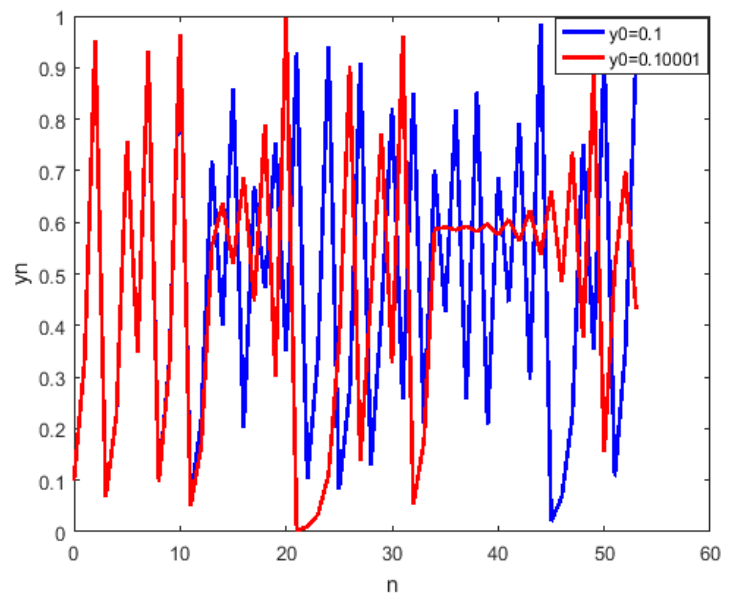

Fig. 4. Chaotic sequence generated for different initial conditions of tent map 
The real values of $y_{n}$ in (13) will be compared with a threshold (c) to get binary sequences as shown in (14) below: [20]

$\mathrm{R}= \begin{cases}0, & 0 \leq \mathrm{y}_{\mathrm{n}} \leq \mathrm{c} \\ 1, & \mathrm{c}<\mathrm{y}_{\mathrm{n}} \leq 1\end{cases}$

The range $[0,1]$ in (14) can be subdivided to $[0, \mathrm{c}]$ and $(\mathrm{c}, 1]$, related to two binary values 0 and 1 as shown in Fig. 5:

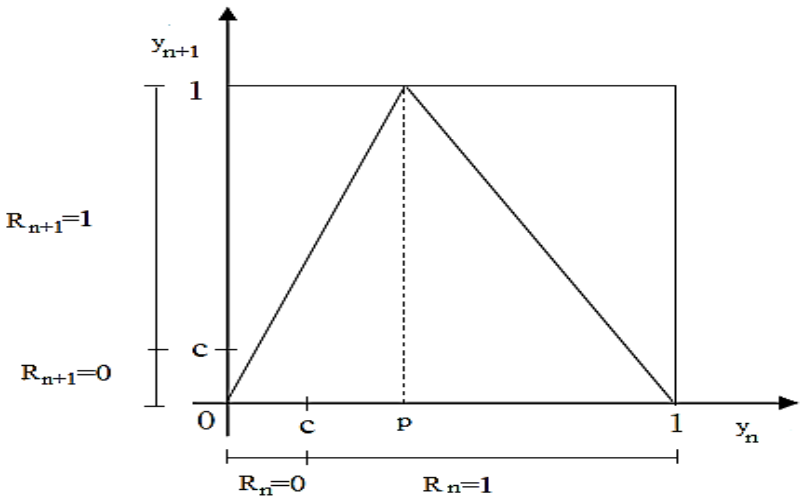

Fig.5. Binary sequences of tent map with threshold $\mathrm{c} \leq \mathrm{p}$

Equation (14), Fig. 5 and the law of uniform probability for tent map, result in the probabilities of the two values 0 and 1 in the sequence $\mathrm{R}$ :

$\mathrm{P}_{0}=\mathrm{P}\left(\mathrm{R}_{\mathrm{n}}=0\right)=\mathrm{P}\left(0 \leq \mathrm{y}_{\mathrm{n}} \leq \mathrm{c}\right)=\mathrm{c}$

$\mathrm{P}_{1}=\mathrm{P}\left(\mathrm{R}_{\mathrm{n}}=1\right)=1-\mathrm{P}\left(\mathrm{R}_{\mathrm{n}}=0\right)=1-\mathrm{c}$

Equation (15) below achieves the statistical independence between any two adjacent values, $R_{n}$ and $R_{n+1}$ in a binary sequence R [20]:

$P\left(R_{n}=a, R_{n+1}=b\right)=P\left(R_{n}=a\right) P\left(R_{n+1}=b\right) \quad a, b \in\{0,1\}$

$\mathrm{P}\left(\mathrm{R}_{\mathrm{n}}=\mathrm{a}, \mathrm{R}_{\mathrm{n}+1}=\mathrm{b}\right)$ shows the probability of simultaneous conditions which $R_{n}=a$ and $R_{n+1}=b$, where $a, b \in\{0,1\}$. By using (14) and Fig. 5, Table I can be calculated. The probabilities of two adjacent symbols of the binary sequence can be shown in Table I when a threshold $\mathrm{c} \leq \mathrm{p}$.

TABLE I

ProbabiLITIES OF Two SUCCESSIVE SYMBOLS $(\mathrm{RN}, \mathrm{RN}+1)$ WHEN C $\leq \mathrm{P}$

\begin{tabular}{|c|c|c|}
\hline$P\left(R_{n}, R_{n+1}\right)$ & $R_{n+1}=0$ & $R_{n+1}=1$ \\
\hline$R_{n}=0$ & $c p$ & $c(1-p)$ \\
\hline$R_{n}=1$ & $c(1-p)$ & $1-c(1-p)-c$ \\
\hline
\end{tabular}

From Table I, (15) can be verified if $c=p$. This means that $R_{n}$ and $R_{n+1}$ binary values have statistical independence between them. Thus, the tent map parameter $\mathrm{p}$ must be within the range $p \in[0.4995,0.5005]$ with $p \neq 0.5$ and a threshold $c=p$ [20]. This leads to obtain APRBS that cannot be practically distinguished because of achieving statistical independence between any two successive symbols in the sequence. Finally, these sequences theoretically and experimentally are tested successfully [20]. Therefore, The suggested APRBS is used in this work to secure data.

\section{B. Convolutional Codes}

The purpose of channel coding in this paper is to protect the SI bits from channel noise and distortion. In the transmitter, convolutional encoding method had been done using trellis diagram with $1 / 2$ code rate. While, V-SDD method is used in the receiver. In this paper, SI bits are 3 bits before encoding $\left(\mathrm{SI}=\log _{2}(\mathrm{M})\right.$, where $\mathrm{M}=8$ as maximum value which used in this paper). After encoding process, the encoded SI bits become 6 bits.

\section{Simulation Results AND SECURITy ANALYsis}

This section will evaluate the performance of the proposed algorithm. At the beginning, simulation results of the proposed algorithm performance will be presented by using MATLAB program. Then, security of the OFDM system using the proposed algorithm will be discussed and analyzed.

\section{A. Simulation Results}

Firstly, PAPR reduction performance will be presented. Secondly, BER performance over AWGN and flat fading channels will be evaluated (without considering the effect of PAPR on BER performance). All parameters that would be used in the simulation process shall be shown in the Table II.

TABLE II

SIMULATION PARAMETERS

\begin{tabular}{|c|c|}
\hline Simulation parameter & Type/value \\
\hline $\mathrm{M}$ & $2,4,6,8$ \\
\hline $\mathrm{N}$ & $128,256,512,1024$ \\
\hline Coding technique & Convolutional code \\
\hline Code rate & $\frac{\mathbf{1}}{2}$ \\
\hline Mod. scheme & BPSK \\
\hline $\mathrm{N}_{\mathrm{CP}}$ (length of cyclic prefix) & $\frac{1}{4} * \mathrm{~N}$ \\
\hline Number of OFDM symbols & 5000 \\
\hline
\end{tabular}

1) PAPR Reduction Performance

Here, PAPR reduction performance has been done in terms of CCDF. Fig. 6 shows CCDF of OFDM signal when $\mathrm{N}=128$ and $\mathrm{M}=0$ (original), $2,4,6$, and 8 .

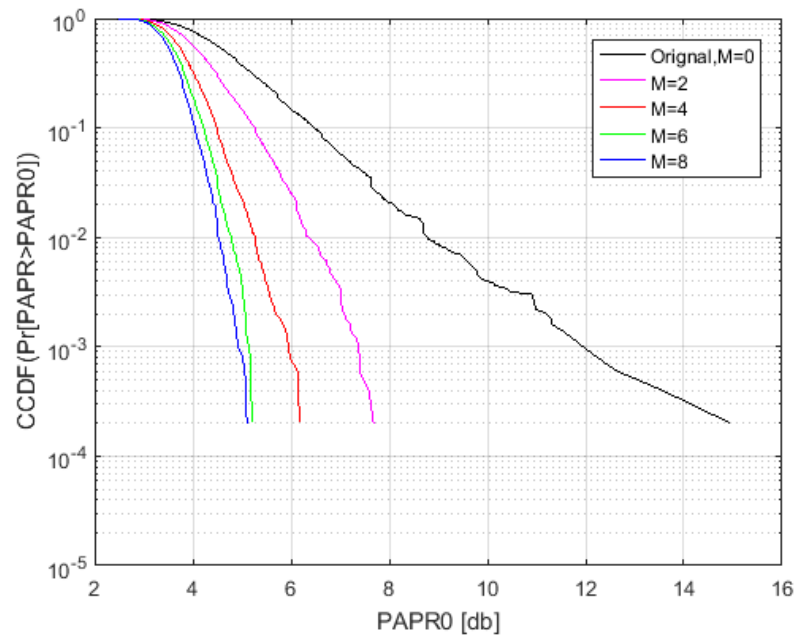

Fig.6. PAPR reduction performance when $\mathrm{N}=128$ and different values of $\mathrm{M}$ 
Fig. 7 below states the PAPR reduction performance of the proposed algorithm when $\mathrm{M}=8$ and different values of $\mathrm{N}$ $(\mathrm{N}=128,256,512$ and 1024).

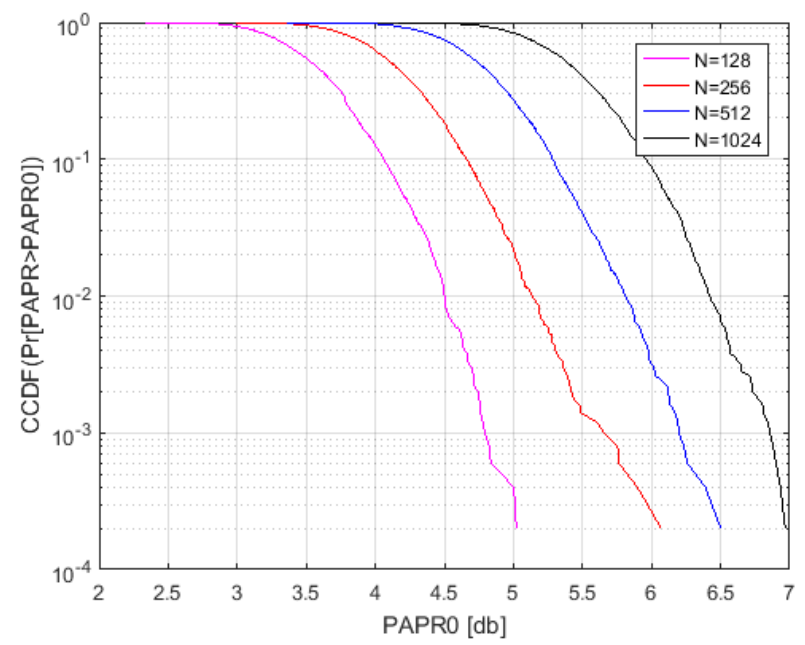

Fig.7. PAPR reduction performance when $\mathrm{M}=8$ and different values of $\mathrm{N}$

Table III below shows the comparison between PAPR reduction performance of the proposed algorithm, the method in [21], and the method in [22].

TABLE III

PAPR REduction Performance of the Propsed Method, the Method in [21], AND THE METHOD IN [22].

\begin{tabular}{|c|c|c|c|}
\hline $\begin{array}{c}\mathrm{N} \\
\text { value }\end{array}$ & $\begin{array}{c}\text { PAPR }(\mathrm{db}) \\
\text { of the } \\
\text { proposed } \\
\text { method } \\
\text { with M=8 }\end{array}$ & $\begin{array}{c}\text { PAPR }(\mathrm{db}) \\
\text { of the } \\
\text { method in } \\
{[21] \text { with }} \\
\mathrm{U}=8\end{array}$ & $\begin{array}{c}\text { PAPR }(\mathrm{db}) \\
\text { of the } \\
\text { method in } \\
\text { [22] with } \\
\mathrm{V}=16\end{array}$ \\
\hline 128 & 5 & 8.09 & $\begin{array}{c}\text { not } \\
\text { discussed }\end{array}$ \\
\hline 512 & 6.5 & 8.38 & 6.5 \\
1024 & 7 & not & 6.9 \\
\hline 56 & discussed & not \\
\hline
\end{tabular}

Comparing with the methods in [21] and [22], PAPR reduction performance of the proposed method is better as shown in Table III. The achieving PAPR reduction performance of the proposed method is little better when comparing it with the method in [22]. But, SI bits when using the proposed method are less because $\log _{2}(\mathrm{M}=8)=3$ bits while $\log _{2}(\mathrm{~V}=16)=4 \mathrm{bits}$ when using the method in [22]. In addition to that, the methods in [21] and [22] require $\mathrm{U}$ or $\mathrm{V}$ blocks of IFFT in the transmitter and FFT in the receiver. This increases the hardware and computational complexities of the system. Regarding any value of $\mathrm{M}$ using the proposed algorithm, only one IFFT block in the transmitter and FFT block in the receiver are required. This means that the hardware and computational complexities when using the proposed method are less comparing with the methods in [21] and [22].

\section{2) BER Performance}

Fig. 8 and Fig. 9 compare the performance of BER for the proposed method and the conventional OFDM system over AWGN and flat fading channels (without considering the effect of PAPR value on BER performance). Here, ten tap-flat fading channel has been used. From these figures, it can be seen that BER performance does not affected by SI when using the proposed method.

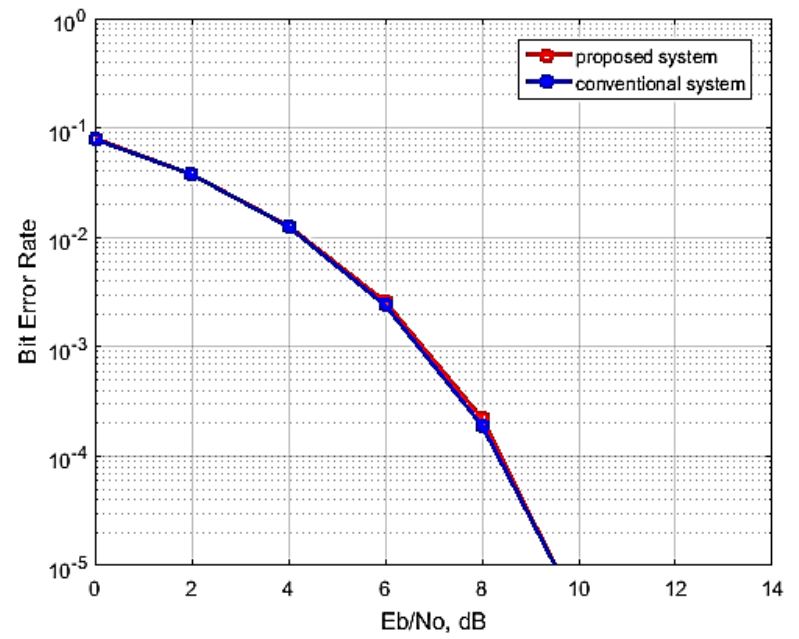

Fig. 8. BER performance comparison over AWGN channel

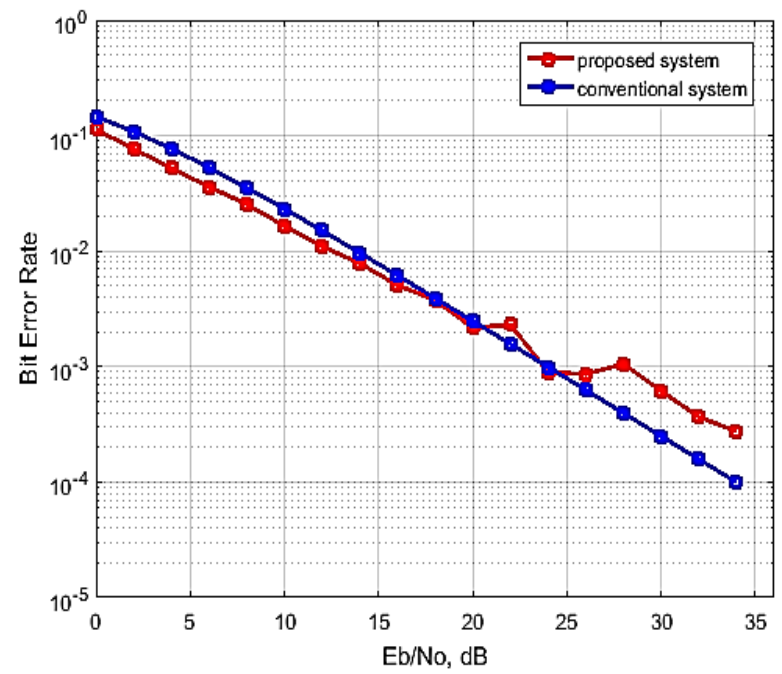

Fig. 9. BER performance comparison over flat fading channel

\section{B. Security Analysis of The OFDM Signal}

The properties of the $\mathrm{APRBS}_{\mathrm{s}}$ are aperiodic long term behavior, random like, independence between any two successive elements, extremely dependence on the initial conditions. Successfully, these sequences had been tested theoretically and experimentally [20]. Because of these properties, it is difficult to be estimated practically by $3^{\text {rd }}$ party (enemy). The $3^{\text {rd }}$ party will face two major challenges to estimate the data. The first challenge is to guess M-initial conditions and M-values of $\mathrm{p}$ parameter which cannot be practically obtained. Table IV shows M-initial conditions and 
M-values of $p$ that used in this paper to generate M-APRBS where $\mathrm{M}=8$.

TABLE IV

M-INITIAL CONDITIONS AND M-VALUES OF P

\begin{tabular}{|c|c|c|}
\hline Index $(\mathrm{m})$ & $\mathrm{y}_{\mathrm{o}}$ & $\mathrm{p}=\mathrm{c}$ (threshold) \\
\hline 0 & 0.1380520796 & 0.499510301 \\
\hline 1 & 0.4730011906 & 0.500367907 \\
\hline 2 & 0.7109620134 & 0.499879881 \\
\hline 3 & 0.2749501358 & 0.499683394 \\
\hline 4 & 0.5201345022 & 0.500254609 \\
\hline 5 & 0.8203714019 & 0.499609842 \\
\hline 6 & 0.3897620013 & 0.500069984 \\
\hline 7 & 0.9012239874 & 0.500100695 \\
\hline
\end{tabular}

The second challenge is to know the selected sequence from M-APRBS $s_{s}$ which would give lowest PAPR value in the OFDM signal for transmission. $3^{\text {rd }}$ party can know only the index of the selected sequence from SI bits. Even though the $3^{\text {rd }}$ party knows SI, he cannot estimate the selected APRBS because there are $2^{\mathrm{M}} * 2^{\mathrm{M}}$ combinations $(256 * 256)$ of 8 $\mathrm{APRBS}_{\mathrm{s}}$ arrangements which the transmitter selects only one of them. Table $\mathrm{V}$ below states all possible arrangements of $\mathrm{M}$ APRBS $_{\mathrm{s}}$ with $2^{8} * 2^{8}$ combinations (65536 combinations). The SI bits can be encrypted by APRBS for adding the difficulty to $3^{\text {rd }}$ party.

TABLE V

All POSSIBLE ARRANGEMENTS OF 8-APRBSS

\begin{tabular}{|c|c|c|c|c|}
\hline 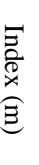 & $1^{\text {st }}$ arrangement & $2^{\text {nd }}$ arrangement & 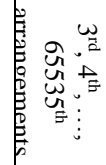 & $\begin{array}{c}65536^{\text {th }} \\
\text { arrangement }\end{array}$ \\
\hline 0 & $\begin{array}{c}y_{n}=0.1380520796 \\
p=0.499510301\end{array}$ & $\begin{array}{c}\mathrm{y}_{\mathrm{n}}=0.9012239874 \\
\mathrm{p}=0.499683394\end{array}$ & $\cdots$ & $\begin{array}{c}\mathrm{y}_{\mathrm{n}}=0.2749501358 \\
\mathrm{p}=0.500069984\end{array}$ \\
\hline 1 & $\begin{array}{c}\mathrm{y}_{\mathrm{n}}=0.4730011906 \\
\mathrm{p}=0.500367907\end{array}$ & $\begin{array}{c}\mathrm{y}_{\mathrm{n}}=0.2749501358 \\
\mathrm{p}=0.499609842\end{array}$ & $\cdots$ & $\begin{array}{c}\mathrm{y}_{\mathrm{n}}=0.4730011906 \\
\mathrm{p}=0.499510301\end{array}$ \\
\hline 2 & $\begin{array}{c}\mathrm{y}_{\mathrm{n}}=0.7109620134 \\
\mathrm{p}=0.499879881\end{array}$ & $\begin{array}{c}\mathrm{y}_{\mathrm{n}}=0.5201345022 \\
\mathrm{p}=0.499510301\end{array}$ & $\cdots$ & $\begin{array}{c}\mathrm{y}_{\mathrm{n}}=0.3897620013 \\
\mathrm{p}=0.500367907\end{array}$ \\
\hline 3 & $\begin{array}{c}\mathrm{y}_{\mathrm{n}}=0.2749501358 \\
\mathrm{p}=0.499683394\end{array}$ & $\begin{array}{c}\mathrm{y}_{\mathrm{n}}=0.8203714019 \\
\mathrm{p}=0.500254609\end{array}$ & & $\begin{array}{c}\mathrm{y}_{\mathrm{n}}=0.1380520796 \\
\mathrm{p}=0.499879881\end{array}$ \\
\hline 4 & $\begin{array}{c}\mathrm{y}_{\mathrm{n}}=0.5201345022 \\
\mathrm{p}=0.500254609\end{array}$ & $\begin{array}{c}\mathrm{y}_{\mathrm{n}}=0.3897620013 \\
\mathrm{p}=0.500069984\end{array}$ & & $\begin{array}{c}y_{n}=0.9012239874 \\
p=0.500100695\end{array}$ \\
\hline 5 & $\begin{array}{c}\mathrm{y}_{\mathrm{n}}=0.8203714019 \\
\mathrm{p}=0.499609842\end{array}$ & $\begin{array}{c}\mathrm{y}_{\mathrm{n}}=0.1380520796 \\
\mathrm{p}=0.499879881\end{array}$ & & $\begin{array}{c}y_{n}=0.5201345022 \\
p=0.499683394\end{array}$ \\
\hline 6 & $\begin{array}{c}\mathrm{y}_{\mathrm{n}}=0.3897620013 \\
\mathrm{p}=0.500069984\end{array}$ & $\begin{array}{c}\mathrm{y}_{\mathrm{n}}=0.4730011906 \\
\mathrm{p}=0.500100695\end{array}$ & & $\begin{array}{c}y_{n}=0.7109620134 \\
p=0.500254609\end{array}$ \\
\hline 7 & $\begin{array}{c}\mathrm{y}_{\mathrm{n}}=0.9012239874 \\
\mathrm{p}=0.500100695\end{array}$ & $\begin{array}{c}\mathrm{y}_{\mathrm{n}}=0.7109620134 \\
\mathrm{p}=0.500367907\end{array}$ & $\cdots$ & $\begin{array}{c}\mathrm{y}_{\mathrm{n}}=0.8203714019 \\
\mathrm{p}=0.499609842\end{array}$ \\
\hline
\end{tabular}

Finally, Fig. 10 shows that the tent map can be affected by changing the $\mathrm{p}$ parameter with the same initial condition. In this figure, $\mathrm{y}_{0}=0.1380520796$ and two different values of $\mathrm{p}$ parameter $(0.499510301,0.500367907)$.

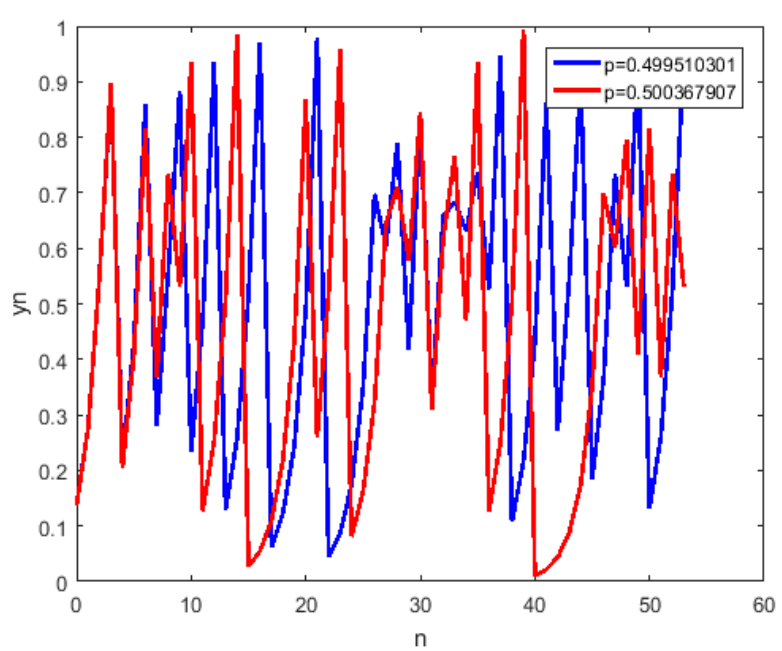

Fig.10. Tent map with constant $y_{n}$ and two different values of $p$ parameter

\section{CONCLUSION}

This paper presents a proposed scrambling algorithm that improves the performance of OFDM system. Comparing with the conventional scrambling techniques (methods in [21] and [22]), the proposed algorithm requires less hardware and computational complexities. Also it achieves good PAPR reduction performance so that when $\mathrm{N}=256$, the reduction in PAPR value when using the proposed method comparing with [21] is $2.31 \mathrm{db}$. As far as the reduction is concerned, it is $0.43 \mathrm{db}$ when comparing with [22]. In addition to that, the proposed algorithm built robust data encryption method to secure OFDM signal against $3^{\text {rd }}$ party. Finally, BER performance of the proposed algorithm OFDM system does not affected by SI due to using the convolutional code with VSDD.

\section{ACKNOWLEDGEMENT}

This work was supported by the Islamic university research grant PRG-IUNAJAF-2019.

\section{REFERENCES}

[1] R. Luo et al, "OFDM Wireless Downhole Transmission Systems and Proposed SLM Method for PAPR Reduction", Communications and Network, Vol. 6 No. 1, 2014, pp. 9-14. DOI:10.4236/cn.2014.61002

[2] R. Rajbanshi et al, "Adaptive-Mode Peak-to-Average Power Ratio Reduction Algorithm for OFDM-Based Cognitive Radio", IEEE Vehicular Technology Conference, Montreal, Que., Canada, 25-28 Sept. 2006. DOI:10.1109/vtcf.2006.282

[3] S. Eom et al, "Low-Complexity PAPR Reduction Scheme without Side Information for OFDM Systems", IEEE Transactions on Signal Processing, vol. 60, no. 7, july 2012, pp. 3657 - 3669. DOI: $10.1109 /$ TSP.2012.2191779

[4] Y. Cho et al, "MIMO-OFDM Wireless Communications with MATLAB", Wiley-IEEE Press, Noida, India, 2010.

[5] C. Lin et al, "A Novel PTS Scheme for PAPR Reduction in OFDM Systems using Riemann Sequence", $3^{\text {th }}$ International Conference on Artificial Intelligence and Computational Intelligence, Taiyuan, China, September. 2011, pp. 554-560. DOI: 10.1007/978-3-642-23887-1_71

[6] Y. Wu et al, "An Overview: Peak-to-Average Power Ratio", IEEE Transactions on Broadcasting, vol. 54 , no. 2, June 2008, pp. 257-268. DOI: $10.1109 /$ TBC.2008.915770

[7] P. Cheng et al, " Improved SLM for PAPR Reduction in OFDM System", IEEE $18^{\text {th }}$ International Symposium on Personal, Indoor and Mobile Radio Communications, Athens, Greece, 3-7 Sept. 2007. DOI: 10.1109/PIMRC.2007.4394556 
[8] A. Goel et al, "M-ary Chaotic Sequence Based SLM-OFDM System for PAPR Reduction without Side-Information", International Journal of Electronics and Communication Engineering vol.6, no.8, 2012, pp.783788

[9] A. P. More et al, "The Reduction of PAPR in OFDM Systems using Clipping and SLM Method", International Conference on Information Communication and Embedded Systems, Chennai, India, 21-22 Feb. 2013. DOI:10.1109/ICICES.2013.6508385.

[10] Z. Wang et al, " Reduction PAPR of OFDM Signals by Combining Grouped DCT Precoding with PTS", Journal of Signal and Information Processing, vol.5 no.4, Nov. 2014, pp.135142.DOI:10.4236/jsip.2014.54016

[11] G. P. Aquino et al, "PAPR Reduction and Performance Improvement in OFDM Systems using WHT-Based Schemes," Journal of Communication and Information Systems, Nov.2017, pp. 146-160. DOI:10.14209/jcis.2017.15

[12] R. V. Nee et al, "OFDM for Wireless Multimedia Communications", Artech House. Boston, London, $1^{\text {st }}$ edition, 30 Dec. 2000

[13] D.W. Lim et al, "on the Phase Sequence Set of SLM OFDM Scheme for A Crest Factor Reduction", IEEE Transactions On Signal Processing, vol. 54, no. 5, May 2006, pp.1931- 1935. DOI: 10.1109/TSP.2006.871979

[14] S. H. Strogatz, "Nonlinear Dynamics and Chaos", CRC Press; 1 edition, 29 Dec., 2000.

[15] Wiggins, "Introduction to Applied Nonlinear Dynamical Systems and Chaos", Berlin: Springer-Verlag, 1990.

[16] S. M. Falih, "A Pseudorandom Binary Generator Based on Chaotic Linear Feedback Shift Register", Iraq J Electrical and Electronic Engineering, vol.12, no.2, 2016, pp.155-160. DOI:10.33762/eeej.2016.118290

[17] M. K. Mahmood et al, "Performance Evaluation of DS-CDMA System Based Orthogonal Chaotic Vectors over Rayleigh Fading Channel", International Journal of Computer Application, vol.114, no. 3, March 2015, pp.8-14.DOI:10.5120/19956-0060

[18] D.M. Kato et al, "On The Power Spectral Density of The Chaotic Signals Generated By Skew Tens Maps", International Symposium on Signals, Circuits and Systems (IEEE), Iasi, Romania, 13-14 July 2007. DOI:10.1109/isscs.2007.4292662

[19] Vlad et al, "A Study on Statistical Independence in The Tent Map", International Symposium on Signals, Circuits and Systems (IEEE), Laşi, Romania, 9-10 July 2009.DOI:10.1109/ISSCS.2009.5206145.

[20] A. Luca et al, "Generating Random Binary Sequences Using tent Map", International Symposium on Signals, Circuits and Systems (IEEE), Iaşi, Romania, 30 June-1 July 2011.DOI: 10.1109/ISSCS.2011.5978664.

[21] U. Khot et al, "Efficient Selective Mapping PAPR Reduction Technique," International Conference on Advanced Computing Technologies and Applications, Mumbai, India, 2015, pp. 620-627. DOI: 10.1016/j.procs.2015.03.117

[22] I. Baig et al, "DCT precoded SLM Technique for PAPR Reduction in OFDM Systems", International Conference on Intelligent and Advanced Systems (IEEE), Manila, Philippines, 15-17 June 2010. DOI: $10.1109 /$ ICIAS.2010.5716107

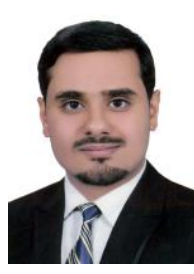

Muntadher Kadhim Abdullah was born in Al-Najaf AlAshraf, Iraq in 1990. He received the B.Sc degree in electrical engineering from Al-Mustansiriya University, Baghdad, Iraq in 2012 and M.Sc degree in electrical engineering/electronic and communication from $\mathrm{Al}$ Mustansiriya University, Baghdad, Iraq in 2014.He is the author of two books and more than 5 articles. His research interests include power electronics, Multi-Carrier techniques, data coding, information security, and wireless communication. Mr. Abdullah worked from 2014 to 2019 as a lecturer in the Islamic University-College of Technical Engineering-Computer Technical Engineering Department, in Najaf, Iraq.

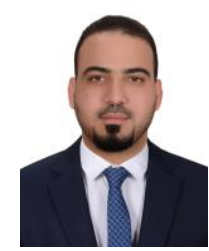

Ali Jawad Ibada, born in Iraq in 1989. He received B.Sc in Computer Engineering Techniques in 2011 from The Islamic University, Iraq. His rank was 1. And received M.Sc in Computer Engineering Techniques in 2015 from Middle Technical University, Iraq. His rank was 1 also. His interests include computer architectures, FPGA design, digital design, programmable logic, modeling and optimization, Fuzzy system, neural networks, Data security, communication protocols, wireless communications, and MultiCarrier techniques. Mr. Ibada, is currently working as a lecturer in the Islamic University - College of Technical Engineering - Computer Technical Engineering Department. in Iraq. 